\title{
Durability of buildings affected by hurricanes
}

\begin{abstract}
The meteorological phenomena impact over many parts of the world during the summer and autumn seasons. Regarding to this impact, all the buildings located in a wide coastal fringe are at permanent risk of suffering damages that may affect their safety and service conditions, as well as their durability. This manuscript reports a briefly introduction that explains the characteristics of hurricanes and is complemented by a discussion about the damage that they cause upon buildings. As a conclusion, for all buildings located in coastal areas, all recommendations suggested by construction codes should be taken to prevent chemical contamination that could be result in a short durability of buildings.
\end{abstract}

Keywords: hurricane, durability, reinforced concrete, corrosion
Volume 2 Issue 6 - 2018

\author{
Romel G Solís Carcaño, Nicolás Zaragoza- \\ Grife J
}

Universidad Autonoma de Yucatan, Mexico

Correspondence: Romel G Solís -Carcaño, Universidad

Autonoma de Yucatan, Mexico, Email tulech@correo.uady.mx

Received: December 07, 2018 | Published: December 17, 2018

\section{Introduction}

Hurricanes are one of the most destructive forces in nature, they rise significate wind forces, causes high tides and sea waves, and intense raining; consequently, hurricanes provoke dynamic pressures, flood and hydric erosion on buildings. The hurricane has its origin as a very strong wind formed over the ocean surface having warm waters, at latitude nearby the equator line; warm and wet wind rises, and it produces an area with lower atmospheric pressure over the ocean surface. In this way, the surrounding air occupies the lower pressure area, becoming warm and humid, and its pressure rises too. As the warm air continues to rise, the surrounding air turns to take its place. When the warm and humid air rises and decreases its temperature, the moisture contained in the air forms the clouds. All cloud and air system spin and gets bigger, and as it spins faster it forms an area well defined with lower air pressure known as the hurricane's eye. ${ }^{1}$ During the developing and maturity phases, the huge hurricane curl is feed with the ocean heat until the hurricane passes over cold water or get into land; When the later occurs, it enters in the dissipation phase and the hurricane rapidly loses its energy and it dissolves fast because of friction caused by its displacement over land. ${ }^{2}$ Many countries are impacted every year by hurricanes developed over the Atlantic and Pacific oceans. This kind of meteorological phenomena, usually provoke significative damage on buildings located in coasts, and cause economic losses in the government as for private owners. Hurricanes usually causes two types of harmful effects in buildings: the direct and immediate damage that occurs during the phenomenon and the chemical contamination, that can affect their durability in the long term. In the first case, when the hurricane touches the coast the buildings are subject to wind pressure, which could be resisted when they are made of heavy materials (masonry or reinforced concrete) and have low height, due to their inertia which generates a highly rigid system. However, the hurricane generates two additional actions in the coastal fringe which can cause the collapse of the buildings: the impact of sea waves and the scouring in the foundation produced by the reflux of sea waves. Finally, chemical contamination occurs because hurricanes in their passage through the coast cause an exceptionally high tide level, which floods urbanized areas with seawater, which is often aggressive for construction materials.

\section{Discussion}

Durability is defined as the attribute of a material or building to resist chemical attacks, abrasion or any other process of deterioration, and which allows it to maintain its strength and original service conditions. ${ }^{4}$ The exposure conditions that cause premature damage to reinforced concrete come mainly from the chlorides and sulfates contained in seawater. Due to the hydrostatic pressure that floods caused by hurricanes generate in the materials, these chemical compounds penetrate their porous network causing various chemical reactions, whose most critical effect are usually the corrosion of the steel rebar and the delamination of the concrete. ${ }^{5}$ Corrosion is defined as the interaction of a metallic material with the surrounding environment, producing changes in its physical and chemical properties. This phenomenon occurs in the presence of an electrolyte, causing anodic and cathodic regions. In the former, an oxidation reaction occurs, by means of which the electrons are released, directing them to the cathodic regions, producing dissolution of the metal at the anode. ${ }^{6}$ The chloride ions are the agent that promotes the destruction of the passivating layer of steel rebar in concrete structures; the coastal environment contains various salts which are dissolved in seawater. More than $55 \%$ of the solid solutes in seawater are chloride ions (Cl-), mainly sodium chloride, and in smaller quantities magnesium chloride, potassium chloride and calcium chloride. Additionally, it must be considered that some chlorides can be introduced into concrete, due to its components, such as: cement and accelerating additives; or also due to the involuntary contamination of water and stone aggregates. ${ }^{3}$

The speed of attack by chlorides varies according to the geographical region according to the concentration of the salts contained in seawater. This depends mainly on three factors: evaporation, rainfall and proximity to river discharges. The range of salinity in the different seas in the world usually goes approximately 30 to 40 grams of salt per liter of solution. ${ }^{7}$ On the other hand, sulfates are chemical compounds that generate deterioration directly to concrete. The main sources of sulfates that can damage the concrete are the waters having industrial waste, and mainly sea water; that's because sea water has a concentration of about 0.004 sodium sulfate. When the concrete has hardened, the sulfate ions entering from the external environment react with the monosulfoaluminates forming the ettringite salt. This salt causes an increase in concrete volume of the order of $250 \%$, which produces great tensions that trigger fissures and superficial detachments of the material. ${ }^{8}$ Some constructive deficiencies provoke an acceleration in the damage caused by the chemical contamination of the materials. Commonly, these deficiencies are: the insufficient coating of the steel rebar and the high permeability of the concrete; these characteristics definitively determine the life span of reinforced concrete and therefore of buildings made with this material. ${ }^{9}$ 


\section{Conclusion}

Buildings on the coast located in areas of high vulnerability to hurricanes have a high probability of being affected by the dynamic loads caused by winds and the scour of their foundations. However, even when design precautions are taken to make them resistant to these actions, experience has shown that chemical contamination reduces their durability. From the durability point of view, these buildings should take all the precautions recommended by the construction codes, mainly the use of a low water-cement ratio, a thick coating on the steel rebar and a long curing period.

\section{Acknowledgments}

None.

\section{Conflicts of interest}

Authors declare that there is no conflict of interest.

\section{References}

1. NASA. How do hurricanes form? 2018
2. Moraleja M. Evolution of a tropical cyclone. 2018.

3. Solís R, Moreno E, Jiménez F, et al. Damage assessment due to environmental aggression in reinforced concrete homes. Ingeniería. 2008;18(1):57-64.

4. Hernández O, Mendoza C. Durability and infrastructure: challenges and socioeconomic impact. UNAM. 2006;7(1):57-70.

5. Lamond J. Designing for durability. Concrete International. 1977;19 (11):34-36.

6. Solís R, Moreno E, Castro P. Durability in the concrete structure of housing in the coastal zone. Engineering: Academic Journal of the Faculty of Engineering Autonomous University of Yucatan. 2005;9(1):13-18.

7. Lewis E. The practical salinity scale 1978 and its antecedents. IEEE Journal of Oceanic Engineering. 1980;5(1):3-8.

8. Castro P. Corrosion in reinforced concrete structures: theory, inspection, diagnosis, useful life and repairs. 2nd edn. Mexico: 2001.

9. Alcocer M. Study of permeability in concrete with crushed limestone aggregates. Mérida, Mexico; Autonomous University of Yucatán: 2014. 